\title{
CRYSTALLOGRAPHIC ANALYSIS OF FUNCTIONALIZED CELLULOSE NANOCRYSTALS
}

\author{
Almeida, J. C. V. ${ }^{1 *}$; da Costa, M. A. ${ }^{1}$; Rodrigues, M. J. ${ }^{1}$; Vasconcelos, N. F. ${ }^{2}$; de \\ Souza Filho, M. S. M. ${ }^{3}$; Rosa, M. F. ${ }^{3}$ \\ ${ }^{1}$ Department of Chemistry and Environment, IFCE, Fortaleza, CE, Brazil \\ ${ }^{2}$ Department of Organic and Inorganic Chemistry, UFC, Fortaleza, CE, Brazil \\ ${ }^{3}$ Embrapa Agroindústria Tropical, Fortaleza, CE, Brazil \\ *claubervalmeida@gmail.com
}

The aim of this work was to analyze functionalized bacterial cellulose nanocrystals (BCNC) by XRD and other techniques, and to quantify the crystallinity index (CI) of the same. BCNC were obtained by $\mathrm{H}_{2} \mathrm{SO}_{4}(50 \% \mathrm{w} / \mathrm{w})$ and $\mathrm{HCl} 36.5 \%(\mathrm{w} / \mathrm{w})(1: 1, \mathrm{v} / \mathrm{v})$ hydrolysis $\left(40{ }^{\circ} \mathrm{C}, 2\right.$ hours, $1: 100 \mathrm{w} / \mathrm{v}$ fibre:solution ratio). The nanostructures were carboxymethylated with $\mathrm{NaOH}$ and $\mathrm{ClCH}_{2} \mathrm{COOH}$ under two different reactional media: ethanol and isopropanol. The functionalized nanocrystals (FBCNC) were analyzed by XRD (Segal et al., 1959), as well as substitution degree (SD) and FTIR. The SD was higher for the samples from isopropanol (1.6) than for the samples from ethanol (1.1). The appearance of a new peak at $1600-1610 \mathrm{~cm}^{-1}$ in the FTIR spectra confirmed the carboxylation of BCNC. The CI of the FBCNC was $54.2 \%$ in ethanol and $26.9 \%$ in isopropanol, showing a reduction in comparison to the BCNC $(89.3 \%)$, because of the substitution of cellulose hydroxyl for carboxymethyl groups. Thus, XRD was efficient for analyze the FBCNC.

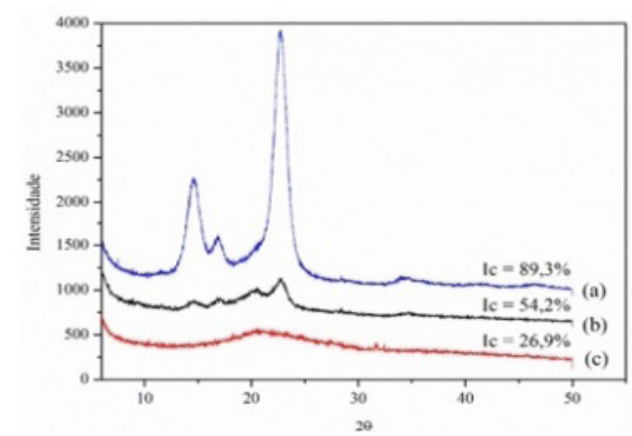

Figure - Diffractograms of (a) bacterial cellulose nanocrystals, (b) carboxymethylated bacterial cellulose nanocrystals in ethanol medium, and (c) carboxymethylated bacterial cellulose nanocrystals in isopropanol medium.

\section{REFERENCE}

SEGAL, L. et al. Textile Research Journal, 29(10), 786-794, 1959. 